O. Kharchenko, PhD

oksanakharchenko@ukr.net,

V. Smok̄al, PhD,

O. Krupka, PhD

A. Kolendo, Dr. Sci.

Taras Shevchenko National University of Kyiv, Kyiv, Ukraine

\title{
KINETIC'S INVESTIGATION OF METHACRYLIC MONOMERS BASED ON 2-STYRYLQUINOLINE
}

Polymethylmethacrylate is widely use material in optics due to its atmosphere resistance, chemical stability, good mechanical properties, transparency and light transmission. Due to these properties, PMMA is often used as a polymeric matrix for creating photosensitive polymers and polymers with nonlinear optical (NLO) properties. Materials with NLO properties can be made by introducing moleculas of chromophores into the polymer chain. There are two fundamentally different ways of doing this. The first is to create composite material where the chromophore is a dispersed phase and is introduced into the system as a "guest". In the second case, the chromophore is introduced into the polymer chain covalently, and can be included in the side and the main chain. Studies of polymers containing NLO chromophore in the side chain have shown a number of advantages: better orientation of the chromophores under the action of an electric field; relaxation processes are much slower; increasing time and thermal stability; increasing the glass transition temperature of the polymer. Based on present knowledge we decided to design new methacrylic polymers with styrylquinoline chromophore in side chain.

The polymerization ability of the new monomers for free radical homopolymerization was investigated kinetically by using dilatometric method. It was found that new 2-styrylquinoline containing monomers are able to homopolymerization with high conversions (63-83 \%). The polymerization was carried out in DMF using 2,2'-azobisisobutyronitrile as initiator at $80^{\circ} \mathrm{C}$ in argon atmosphere. The products of polymerization were characterized by ${ }^{1} \mathrm{H}$ NMR spectroscopy. It was installed that all new monomers have bigger speed of polymerization $\left(\mathrm{K}_{\text {sum }}=1.36-8.33 \times 10^{3} \mathrm{I} / \mathrm{mo}^{\mathrm{m}} \times \mathrm{s}\right)$ then $\mathrm{methyl-}$ methacrylate $\left(K_{\text {sum }}=0.5 \times 10^{3} \mathrm{I} / \mathrm{mo} / \times s\right)$, phenylmethacrylate $\left(K_{\text {sum }}=1.1 \times 10^{3} \mathrm{I} / \mathrm{mol} \times \mathrm{s}\right)$ and similar to polymerization of $2-$ methyl-8-oxyquinoline methacrylate $\left(K_{\text {sum }}=3.28 \times 10^{3} \mathrm{I} / \mathrm{mo} / \times \mathrm{s}\right)$. It was found that speed of polymerization increases with increasing electron donating power of substitute in paraposition of the aromatic ring. It has been proven that presence of electron acceptor group reduces speed of polymerization.

Keywords: 8-methacryloxystyrylquinoline, styrylquinoline-containing monomers, polymerization kinetics.

УДК 541.64

DOI: https://doi.org/10.17721/1728-2209.2019.1(56).11

О. Ніколаєва, канд. хім. наук, avealokin.anel@gmail.com,

Л. Вретік, д-р хім. наук,

Е. Яновська, канд. хім. наук,

Київський національний університет імені Тараса Шевченка, Київ, Україна

О. Кондратенко, асист.

Житомирський державний університет імені Івана Франка, Житомир, Україна

Г. Тун, студ.,

Київський національний університет імені Тараса Шевченка, Київ, Україна

\section{ОСАДОВА КОПОЛІМЕРИЗАЦІЯ 4-ВІНІЛПІРИДИНУ ЗІ СТИРОЛОМ}

Описано визначення реального складу кополімерів 4-вінілпіридину зі стиролом, що утворюються в умовах їх осадової кополімеризації у $\mathrm{CCl}_{4}$. Для цього було проведено кополімеризацію 4-вінілпіридину зі стиролом у різних співвідношеннях. Склад одержаних кополімерів визначали за даними ${ }^{1}$ Н ЯМР-спектроскопії. Виконано порівняння реального складу кополімерів з теоретично розрахованим. Визначено, що кополімери 4-вінілпіридину зі стиролом, одержані осадовою кополімеризацією у ССІ збагачені ланками 4-вінілпіридину. Виявлено, що для вихідного мольного вмісту стиролу, більшого ніж 0,85, неможливо синтезувати осадовою полімеризацією у $\mathrm{CCl}_{4}$ кополімери 4-вінілпіридин:стирол.

Ключові слова: 4-вінілпіридин, стирол, кополімеризація.

Вступ. Предметом інтенсивного дослідження протягом останніх кількох років були методи контрольованої радикальної полімеризації (CRP) такі, як нітроксидопосередкована полімеризація (nitroxide-mediated polymerization), радикальна полімеризація з передачею атома (atom transfer radical polymerization, ATRP), полімеризація зі зворотною передачею ланцюга додаванням-фрагментацією (reversible addition-fragmentation chaintransfer, RAFT).

Автори роботи [1] повідомляють про першу успішну RAFT полімеризацію 2-вінілпіридину (2BП) та 4-вінілпіридину (4ВП). Показано також можливість контрольованого синтезу блоккополімерів 2ВП-4ВП та 4ВП-2ВП у режимі росту ланцюга полі(2ВП) або полі(4VP) [2], що виступали агентом передачі ланцюга з відповідним комономером.

У роботі [2] блоккополімер стирол-блок-4-вінілпіридин з молекулярною масою 98000 г/моль та індексом полідисперсності 1,28 використовувався як стабілізатор дисперсійної полімеризації стиролу в спирті. Такий кополімер може бути використаний як стеричний стабілізатор у дисперсійній полімеризації стиролу завдяки тому, що поєднує гідрофобні властивості полістиролу та гідрофільний характер полі-4-вінілпіридину.

Ґрунтовне дослідження [3] присвячено синтезу блоккополімеру стирол-ВП в умовах реверсивного інгібування нітроксидом ТЕМРО. Маючи на меті з'ясувати оптимальні умови для контрольованого синтезу блоккополімерів у цій системі, полімеризацію вінілпіридину вивчали в різних концентраціях макроініціатора полістиролTEMPO. Аніонна та RAFT-полімеризація були використані одночасно для приготування високомолекулярного амфіфрільного диблоккополімеру на основі гідрофобного стиролу та більш полярних 2-вінілпіридину або 4-вінілпіридину.

Результати та їх обговорення. У статті [4] нами була виявлена та описана сорбційна активність силікагелю з іммобілізованим кополімером до мікрокількостей іонів $\mathrm{Cu}(\mathrm{II}), \mathrm{Cd}(\mathrm{II}), \mathrm{Pb}(\mathrm{II}), \mathrm{Fe}(\mathrm{III}), \mathrm{Ni}(\mathrm{II})$ у статичному режимі проведення сорбції, а також $\mathrm{Ni}(\mathrm{II})$ іонів у динамічному режимі. Кополімер 4-вінілпіридину зі стиролом був in situ іммобілізований на поверхні силікагелю за допомогою гетерогенної радикальної полімеризації. Кріплення кополімеру в поверхневому шарі було підтверджено ІЧ-спектроскопією. Кількість кополімеру на поверхні силікагелю оцінювалась як 25,73 \% мас. за результатами аналізу методами термогравіметрії та динамічної скануючої калориметрії-масспектрометрії. Розташування полімерного шару на поверхні силікагелю було описано за допомогою скануючої електронної мікроскопії.

3 метою визначення реального складу кополімерів 4-вінілпіридину зі стиролом, що утворюються в умовах осадової кополімеризації у $\mathrm{CCl}_{4}$, було проведено модельні дослідження. Для цього одержували кополімери без 
додавання силікагелю. Кополімеризацію стиролу з 4вінілпіридином проводили в запаяних ампулах у середовищі аргону. Готували розчини концентрації 1,02 моль/л у $\mathrm{CCl}_{4}$. Додавали ініціатор азобісізобутиронітрил у кількості 0,00106 моль/л. Інертну атмосфреру створювали, пропускаючи аргон протягом 30 хв. Кополімеризація велась у термостаті Ц1823 при
$\mathrm{T}=75 \pm 0,5^{\circ} \mathrm{C}$. Час кополімеризації становив 3 год. Вихідні мольні співвідношення мономерів (4-вініпіридин : стирол) $=6: 1 ; 5: 1 ; 4: 1 ; 3: 1 ; 2: 1 ; 1: 2 ; 1: 3 ; 1: 4 ; 1: 5 ; 1: 6$.

Для експериментального визначення складу модельних кополімерів зіставляли інтегральну інтенсивність сигналу близько 8,23 м.ч., що відповідає 2 протонам ароматичного кільця ланок 4-вінілпіридину та 7,07 м.ч., що відповідає 2 протонам ланок стиролу (рис. 1).

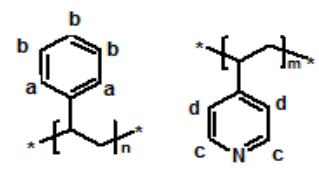

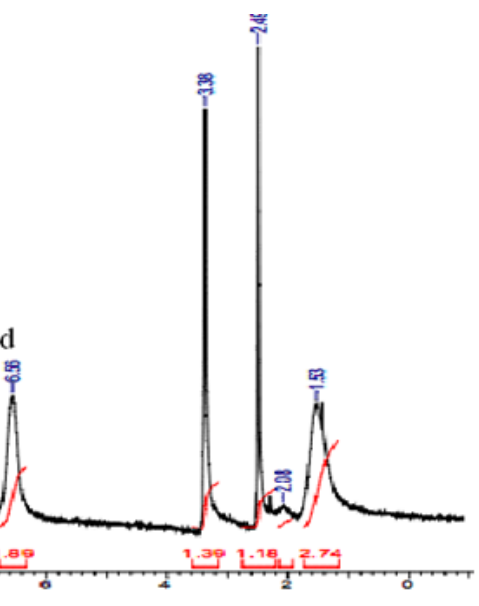

Рис. 1. ${ }^{1} \mathrm{H}$ ЯМР-спектр кополімеру стиролу та 4-вінілпіридину при вихідному мольному співвідношенні 4ВП:СТ=5:1 Робоча частота - 400 МГц, розчинник - ДМСО- $d_{6}$

Умови проведення кополімеризації наведено в табл. 1, експериментально визначений склад модельних кополімерів за даними ${ }^{1} \mathrm{H}$ ЯМР-спектроскопії - у табл. 2.

За експериментальними даними побудовано криву миттєвого складу кополімерів в умовах осадової кополімеризації 4-вінілпіридину зі стиролом у $\mathrm{CCl}_{4}$, граффік наведено на рис. 2.
3 рис. 2 видно, що кополімери 4-вінілпіридину зі стиролом, одержані осадовою кополімеризацією у $\mathrm{CCl}_{4}$, збагачені ланками 4-вінілпіридину.

Умови проведення осадової кополімеризації стиролу (Ст) з 4-вінілпіридином

\begin{tabular}{|c|c|c|c|}
\hline № & Вихідне мольне співвідношення мономерів СТ:ВП & Час полімеризації, години & Вихід, мас. \% \\
\hline 1 & $4: 1$ & 3,0 & 54,46 \\
\hline 2 & $2: 1$ & 3,0 & 5,62 \\
\hline 3 & $6: 1$ & 3,0 & 6,05 \\
\hline 4 & $5: 1$ & 3,0 & 96,80 \\
\hline 5 & $1: 4$ & 3,0 & 6,39 \\
\hline 6 & $1: 2$ & 3,0 & 39,06 \\
\hline
\end{tabular}

Таблиця 2

Розраховані за даними ${ }^{1} \mathrm{H}$ ЯМР-спектроскопії значення $\mathrm{F}_{2}$ (мольні частки ланок 4-вінілпіридину у кополімері) порівняно зі складом вихідної мономерної суміші (f $\mathrm{f}_{2}$ - мольна частка 4-вінілпіридину у вихідній суміші)

\begin{tabular}{|c|c|c|c|c|c|}
\hline VP:ST & $\mathbf{1 : 4}$ & $\mathbf{1 : 2}$ & $\mathbf{2 : 1}$ & $\mathbf{4 : 1}$ & $\mathbf{6 : 1}$ \\
\hline $\mathrm{f}_{2}$ & 0,2 & 0,333 & 0,667 & 0,80 & 0,857 \\
\hline $\mathrm{F}_{2}$ & 0,308 & 0,417 & 0,670 & 0,748 & 0,814 \\
\hline
\end{tabular}

Навпаки, розрахунок миттєвого складу кополімерів за літературними даними [5] показує, що в умовах класичної кополімеризації в розчині 4-вінілпіридин є менш активним, ніж стирол.

Використовуючи рівняння Алфрея - Прайса [6], знаючи для стиролу: $\mathrm{e}_{1}=-0,8$ та $\mathrm{Q}_{1}=1,0$, а для 4-вінілпіридину $\mathrm{e}_{2}=-0,2 ; \mathrm{Q}_{2}=0,82$, ми розрахували теоретичні відносні константи кополімеризації стиролу з 4-вінілпіридином. Одержано такі значення: $r_{1}=1,97 ; r_{2}=0,93$.

Отже, в умовах класичної кополімеризації в розчині 4-вінілпіридин $є$ менш активним, ніж стирол $\left(\mathrm{r}_{2}<\mathrm{r}_{1}\right)$. Це добре ілюструє теоретично розрахована крива залежності "миттєвого" складу кополімерів стиролу (М1) та 4-вінілпіридину (М2) від складу вихідної суміші (див. рис. 2а). Для розрахунку користувались рівнянням

$$
\mathrm{F}_{1}=\frac{\mathrm{r}_{1} f_{1}^{2}+f_{1} f_{2}}{\mathrm{r}_{1} f_{1}^{2}+2 f_{1} f_{2}+\mathrm{r}_{2} f_{2}^{2}}
$$

Теоретично розрахований склад кополімеру наведено в табл. 3.

Теоретично розрахований вміст ланок 4-вінілпіридину в кополімерах зі стиролом

( $F_{2}-$ мольні частки ланок 4-вінілпіридину у кополімері) порівняно зі складом вихідної мономерної суміші

\begin{tabular}{|c|c|c|c|c|c|c|c|c|c|c|c|}
\hline \multicolumn{1}{c}{$\mathbf{f}_{2}$ - мольна частка 4-вінілпіридину у вихідній суміші) } \\
\hline $\mathrm{f}_{2}$ & 0 & 0,1 & 0,2 & 0,3 & 0,4 & 0,5 & 0,6 & 0,7 & 0,8 & 0,9 & 1 \\
\hline $\mathrm{f}_{1}$ & 1 & 0,9 & 0,8 & 0,7 & 0,6 & 0,5 & 0,4 & 0,3 & 0,2 & 0,1 & 0 \\
\hline $\mathrm{F}_{2}$ & 0 & 0,055 & 0,122 & 0,200 & 0,292 & 0,392 & 0,508 & 0,653 & 0,760 & 0,844 & 1 \\
\hline
\end{tabular}




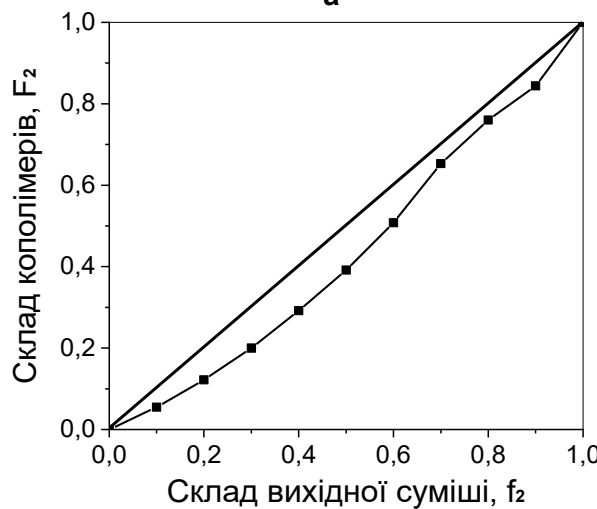

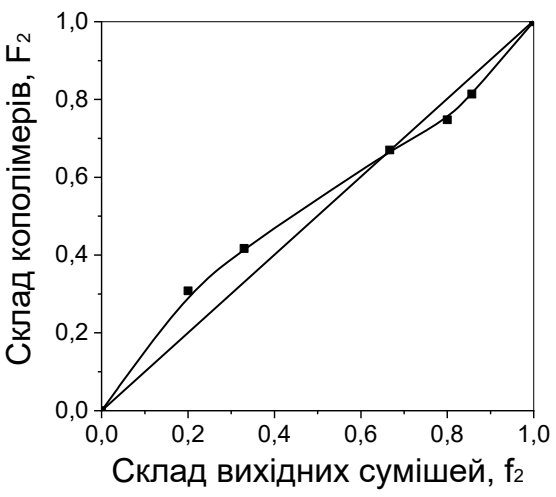

Рис. 2. Залежність "миттєвого" складу кополімерів стиролу $\left(\mathbf{M}_{1}\right)$ та 4-вінілпіридину $\left(\mathbf{M}_{2}\right)$ від складу вихідної суміші: а - теоретична крива для радикальної кополімеризації в розчині;

б - склад кополімеру для осадової кополімеризації у $\mathrm{CCl}_{4}$, розрахований за даними ${ }^{1} \mathrm{H}$ ЯМР-спектроскопії

Висновки. Показано, що кополімери 4-вінілпіридину зі стиролом, одержані осадовою кополімеризацією у $\mathrm{CCl}_{4}$, збагачені ланками 4-вінілпіридину. Знайдено, що для вихідного мольного вмісту стиролу, більшого ніж 0,85, неможливо синтезувати осадовою полімеризацією у $\mathrm{CCl}_{4}$ кополімери 4-вінілпіридин:стирол.

Список використаних джерел

1. Convertine A. J., Sumerlin B. S., Thomas D. B., Lowe A. B., McCormick C. L. Macromolecules. 2003. 36. 4679-4681.

2. Jung Min Lee, Kangseok Lee, Kyungjin Min, Soonja Choe. Curr. Appl. Phys. 2008. 8(6). 732-735.
3. Zaremski M. Y., Chen X., Orlova A. P., Blagodatskikh I. V., Nikonorova N. I. Polym. Sci. Ser. B. 2015. 57. 181-196.

4. Yanovska E. S., Vretik L. O., Nikolaeva O. A., Polonska Y., Sternik D. Kichkiruk O. Yu. Nanoscale Res. Lett. 2017. 12. 217(1-6)

5. Липатов Ю. С. Справочник по химии полимеров. К. : Наук. думка, $1971.536 \mathrm{c}$.

Lipatov Yu. S. Polymer chemistry reference. Kyiv : Naukova dumka, 1971. 536 p. (In Russian).

6. Гетьманчук Ю. П., Сиромятніков В. Г. Практикум з полімерної хімії. К. : Київ. нац. ун-т імені Тараса Шевченка, 2006. С. 33-40.

Getmanchuk Yu. P., Syromiatnikov V. G. Workshop on polymer chemistry. Kyiv : Taras Shevchenko National University of Kyiv, 2006. P. 33-40.

Надійшла до редколегії 27.09.19

Е. Николаева, канд. хим. наук,

Л. Вретик, д-р хим. наук,

Э. Яновская, канд. хим. наук,

Киевский национальный университет имени Тараса Шевченко, Киев, Украина

О. Кондратенко, ассист.,

Житомирский государственный университет имени Ивана Франко, Житомир, Украина

Г. Тун, студ.,

Киевский национальный университет имени Тараса Шевченко, Киев, Украина

\section{ОСАДОЧНАЯ СОПОЛИМЕРИЗАЦИЯ 4-ВИНИЛПИРИДИНА СО СТИРОЛОМ}

Описано определение реального состава сополимеров 4-винилпиридина со стиролом, образующихся в условиях осадочной сополимеризации в СCl4. Для этого была проведена сополимеризация 4-винилпиридина со стиролом в разных соотношениях. Состав полученных сополимеров определяли по данным ${ }^{\top}$ Н ЯМР-спектроскопии. Выполнено сравнение реального состава сополимеров с рассчитанным теоретически. Определено, что сополимеры 4-винилпиридина со стиролом, полученные методом осадочной сополимеризации в ССІ обогащены звеньями 4-винилпиридина. Обнаружено, что при исходном мольном содержании стирола, превышающем 0,85, невозможно синтезировать сополимеры 4-винилпиридин:стирол в $\mathrm{CCl}_{4}$ указанным методом.

Ключевые слова: 4-винилпиридин, стирол, сополимеризация.

O. Nikolaeva, PhD

avealokin.anel@gmail.com,

L. Vretik, Dr. Sci.,

E. Yanovska, PhD

Taras Shevchenko National University of Kyiv, Kyiv, Ukraine,

O. Kondratenko,

Zhytomyr Ivan Franko State University, Ukraine,

G. Tun, Student,

Taras Shevchenko National University of Kyiv, Kyiv, Ukraine

\section{PRECIPITATION COPOLYMERIZATION OF 4-VINYLPYRIDINE AND STYRENE}

The determination of the copolymers of 4-vinylpyridine with styrene copolymers real composition, formed under the conditions of precipitation copolymerization in $\mathrm{CCl}_{4}$, is described. For this, 4-vinylpyridine with styrene was copolymerized in different ratios. The composition of the obtained copolymers was determined according to ${ }^{1} \mathrm{H}$ NMR spectroscopy. A comparison of the real copolymers composition with the theoretically calculated ones was performed as well. The copolymerization of styrene with 4-vinylpyridine was carried out in sealed ampoules in argon medium. Solutions of a concentration of $1.02 \mathrm{~mol} / \mathrm{l}$ in $\mathrm{CCl}_{4}$ were prepared. The initiator azobisisobutyronitrile in the amount of 0.00106 mol/l was added. The copolymerization was carried out in a thermostat C1823 at $T=75 \pm 0.5^{\circ} \mathrm{C}$. The copolymerization time was 3 hours. The original ratio of monomers (4-vinylpyridine:styrene) $=6: 1 ; 5: 1 ; 4: 1 ; 3: 1 ; 2: 1 ; 1: 2 ; 1: 3 ; 1: 4 ; 1: 5 ; 1: 6$. The composition of the obtained copolymers was determined according to ${ }^{1} \mathrm{H}$ NMR spectroscopy. It was determined that copolymers of 4-vinylpyridine with styrene obtained by precipitation copolymerization in $\mathrm{CCl}_{4}$ were enriched by 4 -vinylpyridine bonds. On the contrary, the calculation of the instant composition of the copolymers according to the literature shows that under the conditions of classical copolymerization in 4-vinylpyridine solution is less active than styrene. We calculated the theoretical relative constants of copolymerization of styrene with 4-vinylpyridine: $r_{1}=1.97 ; r_{2}=0.93$. Therefore, under the conditions of classical copolymerization in solution 4-vinylpyridine is less active than styrene $\left(r_{2}<r_{1}\right)$. It was also found out that for the original molar content of styrene if it is greater than 0,85 , it is not possible to synthesize by means of precipitation polymerization into $\mathrm{CCl}_{4}$ the copolymers of 4-vinylpyridine:styrene.

Keywords: 4-vinylpyridine, styrene, copolymerization. 